\title{
2949. Performance improvement of piezoelectric materials in energy harvesting in recent days - a review
}

\author{
Varadha $E^{1}$, Rajakumar $S^{2}$ \\ Department of Mechanical Engineering, Anna University Tirunelveli Regional Campus, \\ Tiruneveli, Tamil Nadu, India \\ ${ }^{1}$ Corresponding author \\ E-mail: ${ }^{1}$ varadha.1604@gmail.com, ${ }^{2}$ rajkumar1998@yahoo.co.in
}

Received 19 November 2017; received in revised form 19 March 2018; accepted 20 April 2018 DOI https://doi.org/10.21595/jve.2018.19434

Check for updates

Copyright $(C) 2018$ Varadha E, et al. This is an open access article distributed under the Creative Commons Attribution License, which permits unrestricted use, distribution, and reproduction in any medium, provided the original work is properly cited.

\begin{abstract}
Piezoelectric elements are inevitable in modern day physics playing a vital role in many applications. Any piezoelectric element requires compression to produce energy in the form of a weak electrical ac signal. Mechanical vibrations are known to cause deflections which are enough to produce energy from the piezoelectric materials. In this paper, a review of the piezoelectric materials is made on their basic modes of excitation for producing energy. Also, various mechanisms and techniques used to harvest energy recently are presented and discussed extensively. Piezoelectric energy harvesting using MEMS is emphasized much as this is the era of micromechanical systems. Most of the piezoelectric energy harvesting systems relies on cantilever-oriented deflection to produce maximum vibration. In general cantilever beams fitted with piezoelectric materials produce electrical energy from mechanical vibration when deflected; hence detailed review on the different shapes of cantilever is also submitted. Significant parameters contributing to improved performance are dealt with special importance.
\end{abstract}

Keywords: cantilever beam, piezoelectric, energy harvesting, wind velocity, frequency and vibration.

\section{Introduction}

In the modern era of blooming inventions, energy sources play a major role in accompanying their achievements. Justifications are already done in moving from conventional to non-conventional sources [1]. As the era of conventional sources is said to be almost over due to its emissions and its state of high alert in depletion, the research in interdisciplinary fields are made on new discoveries and inventions in non-conventional sources [2]. Various researches are conducted mainly on the fields of wind [3], solar [4], tidal [5], ocean [6], fuel cells [7], rain [8], geothermal [9], bio fuels [10] and also hybrid systems [11]. Apart from the disadvantages of conventional sources, these non-conventional sources hold pride for many advantages like pollution free, easily available, non-depleting in spite they are also exploited badly [12, 13]. The modern era has tempted the scientists to integrate one or more green energy sources to get uninterrupted output curbing its limitations. One such integration is our proposed piezoelectric wind harvesting device combining the properties of piezoelectric devices. Piezoelectric elements usually convert the mechanical strain into weak electrical output. Both direct and reverse piezoelectric effect is possible with these elements as shown in Fig. 1 [14].

Naturally some weak undefined electric output signal exists from a piezoelectric crystal for various input sources. The weak output signal can be properly used if transformed and applied appropriately. Some of the common input sources and their corresponding output frequency are tabulated $[15,16]$.

The maximum resistance, for any piezoelectric vibration harvesting system is given by Kim $[17,18]$ :

$R_{o}=\frac{1}{2 \pi f c}$ 
where $f$ - frequency of the vibration and $C$ - capacitance of the piezoelectric element. In Eq. (1) the damping and dielectric loss factor are neglected.

The charge stored on the piezoelectric component times the frequency gives the maximum current flowing through it [19]:

$I=f Q$,

where $f$ - frequency of the piezoelectric element and $Q$ - charges stored in the piezoelectric element.

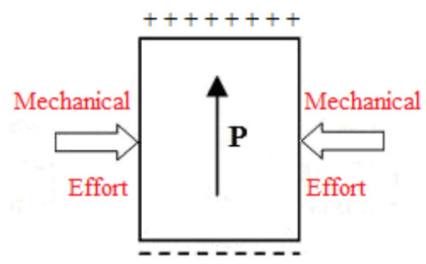

Change Apparition

a) Direct piezoelectric effect

Fig. 1. Direct and reverse piezoelectric effect [14]

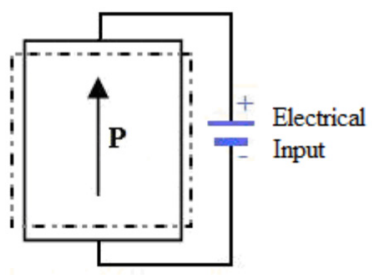

Shape Deformation

b) Reverse piezoelectric effect

Table 1. Peak frequency and acceleration for various energy sources $[15,16]$

\begin{tabular}{|c|c|c|}
\hline Energy sources & Peak frequency $(\mathrm{Hz})$ & Acceleration $\left(\mathrm{m} / \mathrm{s}^{2}\right)$ \\
\hline Human walk & 2 & 0.4 \\
\hline Door closing & 125 & 3 \\
\hline Blender & 121 & 6.4 \\
\hline Microwave oven & 121 & 2.5 \\
\hline Washing and drying machine & 121 & 3.5 \\
\hline Passenger automobile & 200 & 12 \\
\hline Car instrumental panel & 13 & 3 \\
\hline
\end{tabular}

Transduction techniques are classified into three types piezoelectric, electromagnetic and electrostatic or hybrid (combination of any two) [20]. Except electrostatic, the other two are widely used in vibration harvesting. Piezoelectric type has the maximum energy storage density and electrostatic type has the least energy storage density [21].

Some of the broad classifications of piezoelectric materials that we rely for harvesting energy are.

Based on the excitation mode, Natural and Forced or External mode are widely used. Natural excitation is the method in which input mechanical force is fed naturally leaving the system undisturbed whereas in the case of latter, the input mechanical force is given externally which requires attention [22]. Natural excitation is not favored as it produces very less input vibration [23]. Hence most of the systems employing piezoelectric sensors are externally excited.

Based on layering of materials in cantilevers, the cantilevers are classified into unimorph and bimorph in which bimorph can be further classified as series and parallel. Unimorph is a cantilever structure which is a combination of one active and one passive layer, whereas bimorph is a cantilever structure which combines two active layers or two active layers with a passive layer in between them $[24,25]$. The active layer can be made up of any piezoelectric material like Zinc Oxide $(\mathrm{ZnO})$ or s Lead Zirconium Titanate (PZT). In a parallel bimorph, the polarization direction is parallel and electrically parallel connection is seen, whereas in serial bimorph, the polarization direction is opposite, and it is serial connection is seen.

Some of the author's findings are tabulated which shows the type of material used for maximum power generation. 


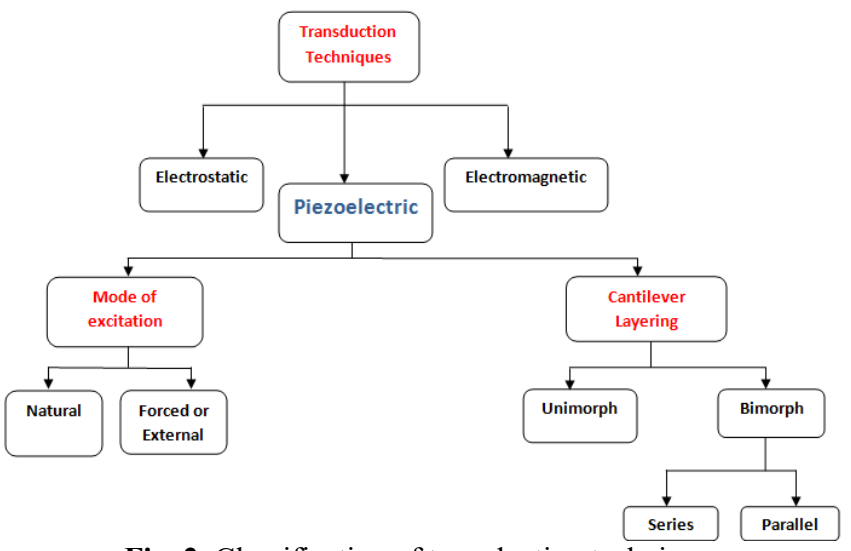

Fig. 2. Classification of transduction techniques

Table 2. Summarization of maximum output generated on using various piezoelectric materials

\begin{tabular}{|c|c|c|}
\hline Author & Material & Maximum power/Current \\
\hline Fei Fei [27] & Flexible belt & $7 \mathrm{~mW}$ \\
\hline Tao [30] & PZT & $150 \mathrm{~W}$ \\
\hline Hyun Jun Jung [23] & PZT & $2.4 \mathrm{~mW}$ \\
\hline Shuguang Li [28] & PVDF element & $296 \mu \mathrm{W}$ \\
\hline Xing qiang Zhao [48] & Al/ AlN/ Mo & $0.342 \mu \mathrm{W}$ \\
\hline Mukhanov [19] & PZT & $0.57 \mathrm{nW}$ \\
\hline Franco [65] & Piezoceramic & $7 \mathrm{~mW}$ \\
\hline Prashanthi [47] & Nanocomposite & $0.025 \mu \mathrm{W}$ \\
\hline Praveen P Nayak [29] & PZT C-203 & $142 \mu \mathrm{W}$ \\
\hline Jiantao Zhang [54] & PVDF & $2566.4 \mu \mathrm{W}$ \\
\hline Shanshan Li [78] & PVDF & $0.35 \mu \mathrm{W}$ \\
\hline Jiang xin Zhao [79] & PVDF & $1.73 \mathrm{~mW}$ \\
\hline Hong jin Wang [40] & PZT & $452.5 \mu \mathrm{A}$ \\
\hline Nicola Heidrich [38] & Aluminium Nitride & $10 \mu \mathrm{W}$ \\
\hline Jihyun Bae [22] & Polytetra fluoroethylene (PTFE) & $0.86 \mathrm{~mW}$ \\
\hline Nan Chen [81] & PZT & $3.9 \mathrm{~mW}$ \\
\hline
\end{tabular}

\section{Natural excitation}

Using naturally available resources, it is possible to excite the piezoelectric materials. Wind energy can excite piezoelectric structures, inducing input vibration [26]. Wind energy into electrical energy conversion using piezoelectric elements follows the following equation [27]:

$P=\frac{1}{2} \rho U^{3}$,

where $P / A$ is power density: $P$ - density of air, $U-$ wind velocity.

Shuguang Li et al. [28, 29] fabricated a flapping leaf generator made of Polyvinylidene Fluoride (PVDF) working like a cantilever pendulum model converting wind energy into electrical output. Series of experiments as shown in Fig. 3 were conducted on different prototypes like horizontal/vertical stalk leaf and long/short single /multiple layers stalk on various directions of airflow with velocity ranging from $2-8 \mathrm{~m} / \mathrm{s}$. Results proved that short single layered vertical PVDF stalk produced more output $296 \mu \mathrm{W}$ at $8 \mathrm{~m} / \mathrm{s}$ for $10 \mathrm{M} \Omega$ load.

Hyun Jun Jung et al. [23] designed and developed a piezoelectric impact-based micro wind generator. For increasing its durability, he compared the simulated results with the experimental results and found stress concentration at the free end prototype lasted for 40 hours and produced 
$2.4 \mathrm{~m} / \mathrm{s}$ on resistive loads at $2 \mathrm{~m} / \mathrm{s}$ producing the best results on 6 comparison samples, as shown in Fig. 4.

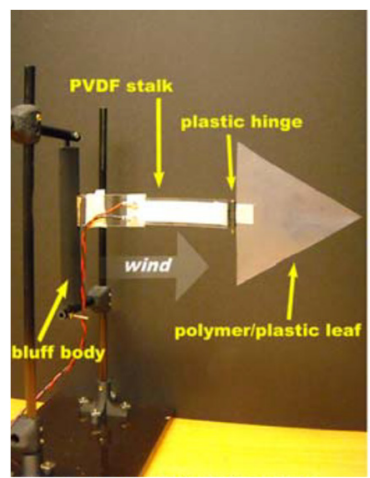

a) Horizontal-stalk leaf

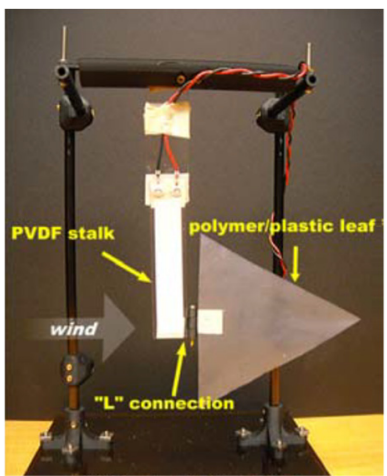

b) Vertical-stalk leaf

Fig. 3. Experimental set up of Shuguang Li [28]

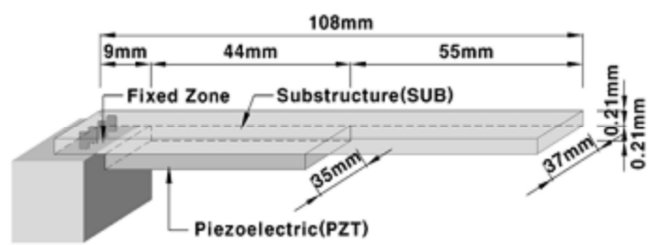

a)

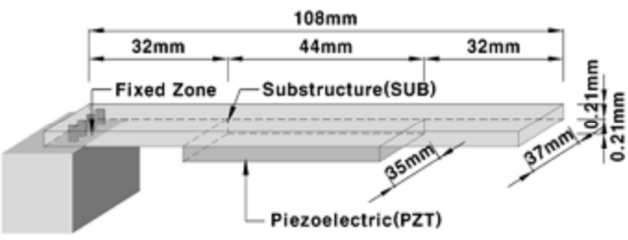

c)

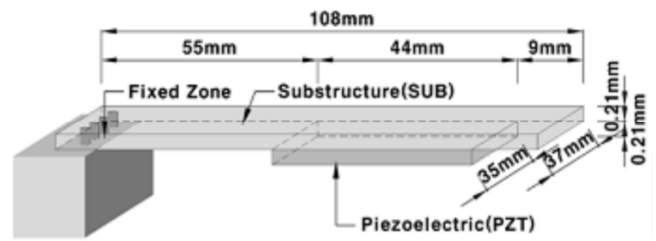

e)

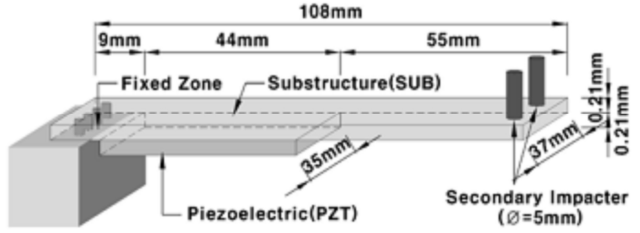

b)

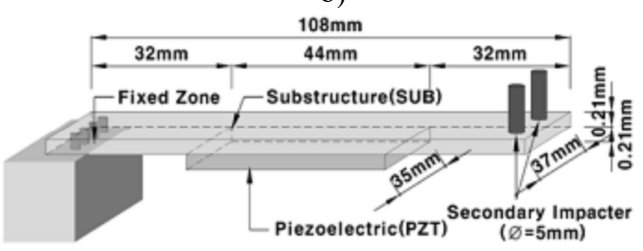

d)

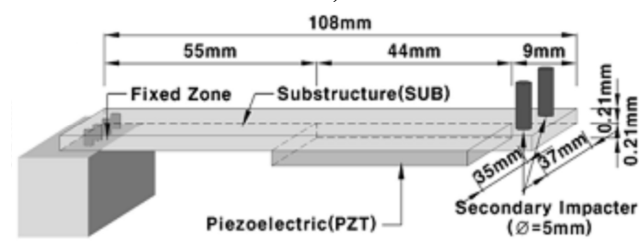

f)

Fig. 4. Six comparison geometries [23]

J. X. Tao et al. [30] constructed a wind mill as shown in Fig. 5(a), (b) that works on Scotch yoke mechanism connected to the shaft blades operates on a spring which is attached to a piezoelectric bar. Here the output increases with increase in the ratio of moment arms of the lever, stiffness of the springs and angular velocity of the wind turbine, the power output also increases. Experiments showed a decrease in voltage with increase in width and length of the piezoelectric bar. The wind mill produced a maximum output of $150 \mathrm{~W}$ at $7.2 \mathrm{~m} / \mathrm{s}$ when designed with a $1 \mathrm{~m}$ long blade for an angular velocity of $50 \mathrm{rad} / \mathrm{s}$.

A aquasi-resonant rectifier is designed for capturing power from a freely fluttering PVDF uni-morph is investigated and significant change is noticed in increasing the power output after the wave is fully rectified [31].

Researchers have also experimented using multiple harvesters [32], McCarthy et al. [33] 
proved that the trailing harvester produced 20 percent [34] and 40 percent [35] more power when two harvesters are placed in tandem.

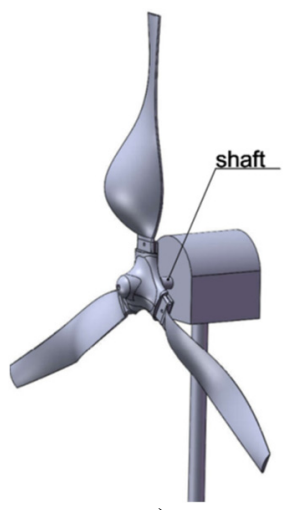

a)

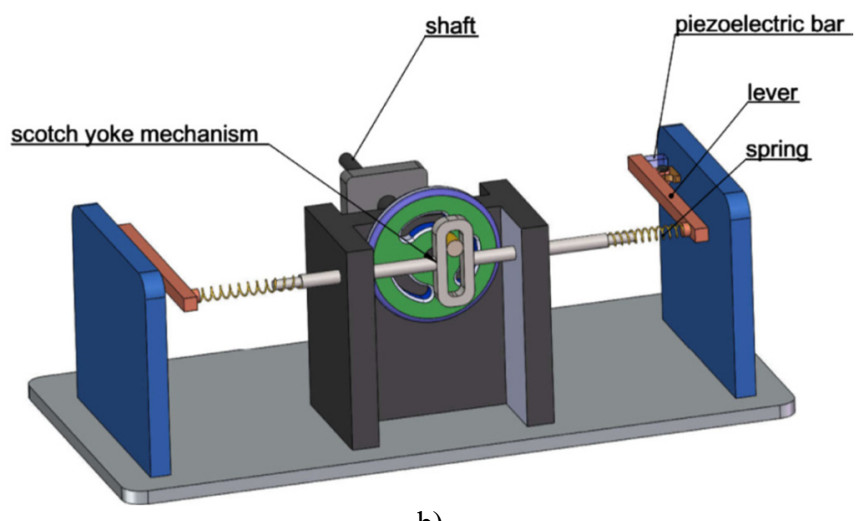

b)

Fig. 5. a) the device overview device, and 4, b) internal working structure [30]

Fei Fei et al. [27] designed and fabricated a wind energy harvesting system that converts flutter energy which is induced aerodynamically, as shown in Fig. 6. It consists of an exclusively designed belt which converts the wind energy into vibrations, electromagnetic resonator set consisting of a permanent magnet and coils with springs which are optimized to produce best results.

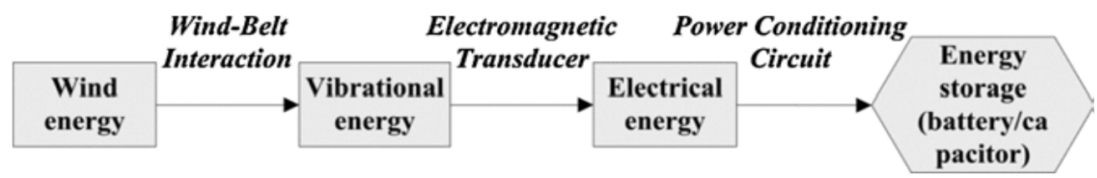

Fig. 6. Conversion mechanism of the wind energy harvesting system [27]

Further on enhancing the power conditioning devices, he produced an output of approximately $7 \mathrm{~mW}$ at $2.8 \mathrm{~m} / \mathrm{s}$. Experimental results showed effective results for higher spring constant on high wind velocity as the electromagnetic coupling is stronger and better excitation forcing frequency.

Table 3. Tabulated results of velocity vs maximum power

\begin{tabular}{|c|c|c|}
\hline Author & Velocity $(\mathrm{m} / \mathrm{s})$ & Maximum power obtained $(\mathrm{W})$ \\
\hline Tao [21] & 7.2 & 150 \\
\hline Robbins [22] & 15 & $1.00 \mathrm{E}-02$ \\
\hline Shuguang Li [23] & 8 & $6.00 \mathrm{E}-01$ \\
\hline Bryant [24] & 8.1 & $1.54 \mathrm{E}-03$ \\
\hline McCarthy [26] & 8 & $1.00 \mathrm{E}-03$ \\
\hline McCarthy [27] & 8 & $1.40 \mathrm{E}-05$ \\
\hline Fei Fei [28] & 3 & $7.00 \mathrm{E}-03$ \\
\hline
\end{tabular}

\section{External excitation}

External or forced excitation is a classic method but practiced till now, as the generated output is significantly high compared to the natural excitation [36]. By combining electromagnetic resonance with piezoelectric resonance, a wireless excitation for piezoelectric device is achieved, When the operating frequency of the helical antenna like structure as shown in Fig. 7 coincides with that of the external capacitor maximum excitation has been observed. The results obtained using analytical studies found to match with the experimental results. Since this technique is flexible and compact it has many potential applications [29]. 
A beam-roller configuration as shown in Fig. 8(a), (b) is designed to achieve a PEH that can scavenge energy from sway and bi-directional vibrations. Sway of the frame is sensed by the roller and the energy captured by it is coupled to beam by magnetic coupling. The beam does the piezoelectric conversion. Frequency-up conversion is also achieved by this configuration. In order to predict voltage output of the beam lumped parameter model is used [37].

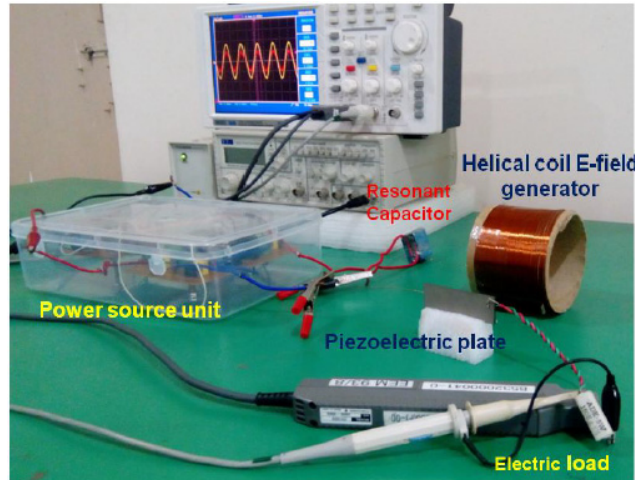

Fig. 7. Experimental set up of helical antenna coil power harvesting system [29]

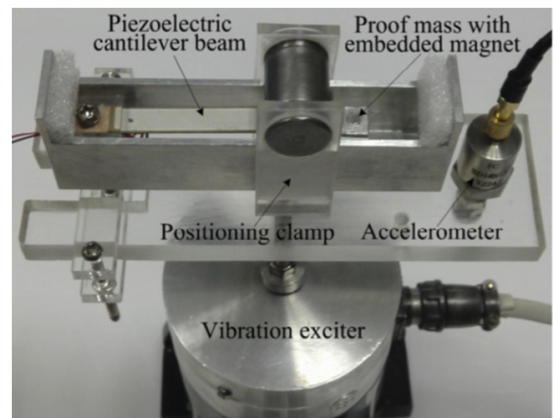

a)

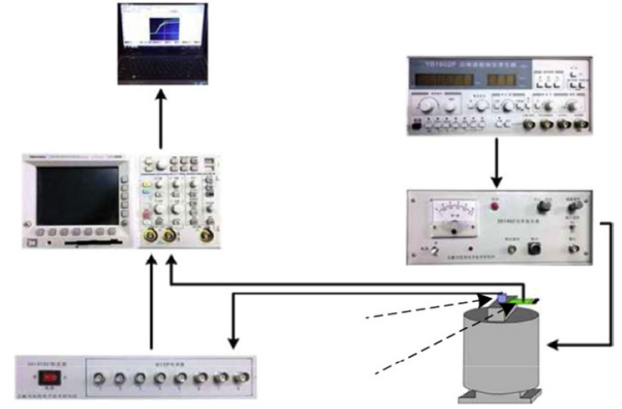

b)

Fig. 8. a) Beam roller Piezoelectric harvester, b) experimental set up [37]

Using corrugated membranes made from aluminum nitride, non-resonant piezoelectric micro energy harvesters have been designed. The efficiency of this non-resonant system is compared to conventional resonant structures. For evaluating the conversion efficiency, the characterization of these harvesters is done using laser Vibrometer for two modes of mechanical excitation. In order to calculate the feasible energy outcome and to optimize the electro mechanical coupling classical analytical modelling has been used to describe the corrugated Microsystems [38].

An Energy harvester has been designed using three piezoelectric layers with different masses. A permanent magnet is attached to the end of each layer and they have a $120^{\circ}$ Phase shift. Since the magnets do not come into contact with each other overall lifetime of the system is improved. Experiments are conducted by using resistive loads of $R_{L}=1 \mathrm{M} \Omega$ and $100 \mathrm{k} \Omega$ for various speeds of wind.

The results as shown in Fig. 9 prove that power can be harvested for low wind speeds such as $1.75 \mathrm{~m} / \mathrm{s}$. However, the total harmonic distortion is quite high though $20 \%$ of them can be restored back using a capacitor. It is found that thicker piezoelectric improve overall efficiency [39]. An analytical model is designed to determine the dynamic behavior of an electromechanical piezoelectric bimorph cantilever harvester as shown in Fig. 10 which is connected to an AC-DC circuit. The model is based on Euler-Bernoulli beam theory and Hamiltonian Theorem. The proposed bimorph structure has a plug-type connection between the support layer and tip mass. This ensures the centre of gravity of the tip mass is collinear with that of the beam thereby 
eliminating the brittle fracture between the piezoelectric layers while vibrating with large amplitude. Theoretical analysis is validated by experimental results [40].

Proof mass is attached at the cantilever beam tip and experimental and simulated results are compared on the basis of thin beam theory $[41,42]$.

Patel et al., experimented on a rectangular cantilever by applying constant acceleration at a weight of $2 \mathrm{~g}$ and concentrated on the control parameters, tip mass inertia and substrate thickness mainly [43].

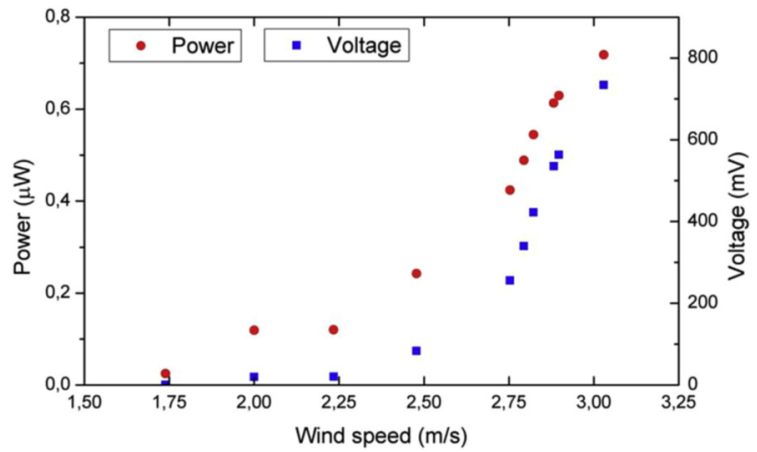

Fig. 9. Voltage and power at various wind speeds [39]

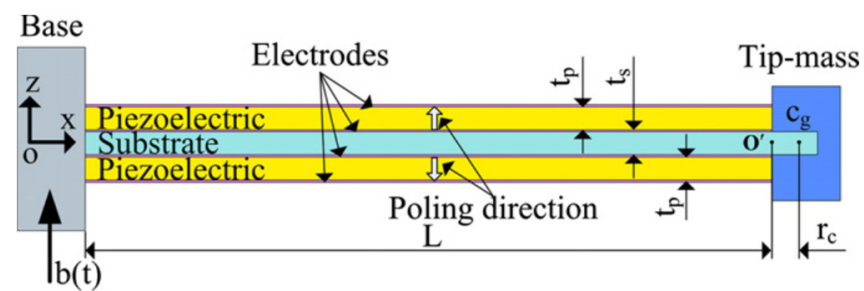

Fig. 10. Designed piezoelectric bimorph [33]

\section{Cantilever beam configuration}

Cantilever selection is vital in harvesting the maximum possible energy as the amount of the deflection is related to it. Various configurations of cantilever have been used by the researchers to produce the maximum deflection.

The governing equation for any uniform beam undergoing undamped free vibration is given by [44]:

$E I \frac{\partial^{4} Z(X, t)}{\partial X^{4}}+m \frac{\partial^{2} Z(X, t)}{\partial t^{2}}=f_{0}(X, t)$,

where $E I$ - bending stiffness and $m$ - beam's mass per unit length.

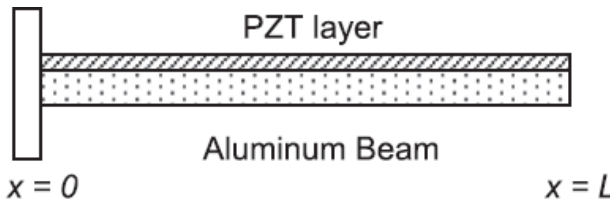

Fig. 11. Rectangular Cantilever beam harvesting energy [44]

The transverse displacement of the neutral axis (at point $x$ and time $t$ ) due to bending for a Rectangular Cantilever beam as shown in Fig. 10 is represented as $z(x, t)$.

The natural frequency of the rectangular cantilever beam at $k$ th mode is given by: 
$\omega_{k}=\lambda_{k}^{2} \sqrt{\frac{E I}{m L^{4}}}$.

To find out the amplitude of any oscillating Cantilever beam [45]:

$A=\frac{F L^{3}}{3 E I}$

where $F$ - the force acting on the beam which keeps on the oscillation.

By using forced vibration analysis, the voltage response of the piezoelectric element attached to the rectangular cantilever beam is calculated [44]:

$\frac{V(t)}{-\omega^{2} Y_{0} e^{j \omega t}}=\frac{\sum_{k=1}^{\infty} \frac{j m \omega \varphi_{k}\left(\int_{0}^{L} W_{k}(X) d X\right)}{\omega_{k}^{2}-\omega^{2}+j^{2} \zeta_{k} \omega_{k} \omega}}{\left\{\sum_{k=1}^{\infty} \frac{j \omega x_{k} \varphi_{k}}{\omega_{k}^{2}-\omega^{2} j^{2} \zeta_{k} \omega_{k} \omega}\right\}+\frac{1+j \omega \zeta_{c}}{\zeta_{c}}}$,

where: $\omega$ - frequency and, $j$ - unit imaginary number, $\varphi_{k}-$ constant, $V_{0}$ - voltage amplitude, $\tau_{c}$ is the time constant of the circuit.

Nan Chen et al. found that much of energy is wasted in the form of losses in most of the harvesting devices. Hence, he presented a paper with 48 cantilever beams made of piezoelectric material to form a harvester that works on low frequency input. This set up is installed to produce energy from it when a car passes over it. In order to avoid losses, the experimental set up is designed to work on two modes, awake mode and sleep mode. Experiments are done varying the transmission times of the car, contact time, mode changing, and the speed of the car as shown in Fig. 12. Special care is also given for designing the electrical circuit, storing the harvested power and calculating their efficiencies [46].

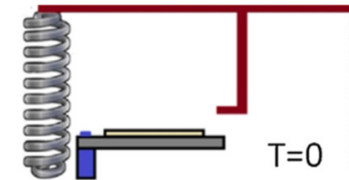

a) Origin

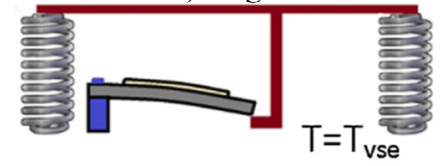

c) Impact period ending

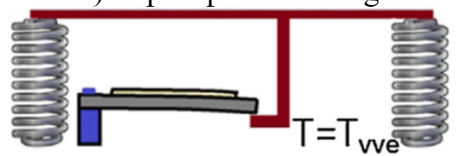

e) Impact period starting

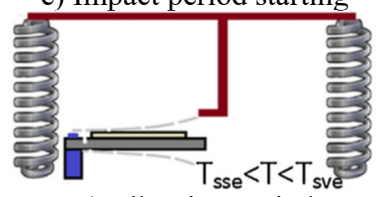

g) Vibration period

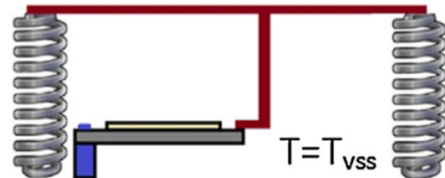

b) Impact period starting

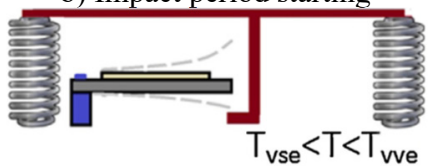

d) Vibration period

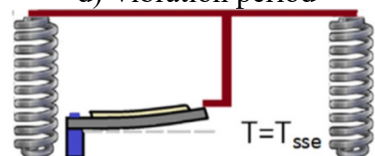

f) Impact period ending

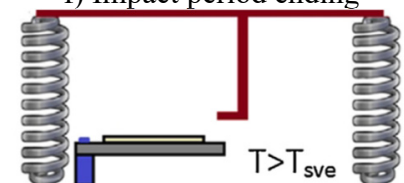

h) Origin

Fig. 12. Operation of cantilever on various process [46]

To improve the electrical conductivity of the cantilevers, Prashanthi et al. fabricated $\mathrm{ZnO}$ 
nanocomposite cantilevers which are photo patternable [47]. Xingqiang Zhao et al. fabricated 5 different micro cantilever beams using Aluminum, aluminum Nitride and molybdenum multilayers and tested them using an electromechanical shaker. Experiments are conducted for Series and parallel combinations when converting them to DC. He found that series connections can reduce the power loss during rectification [48]. Liaosha Tang et al. designed and found a new harvesting device which utilizes the flutter motion for converting into electrical power. The fluid flow and plate energy transfer relationship are dealt which uses cantilever flexible plates. Mass ratio and velocity are taken as key parameters for the above design [49].

Based on Hamilton principle, Hong-Xiang Zou et al developed a two degree of freedom energy harvesting device consisting of inverted piezoelectric flags, magnetically coupled as shown in Fig. 13 which is suited for low speed rotation. The average output power output for the first piezoelectric flag is 564 microWatts and for the latter one 535.3 microWatts [50].

Table 4. Shape evaluation of Cantilever beams and its performance

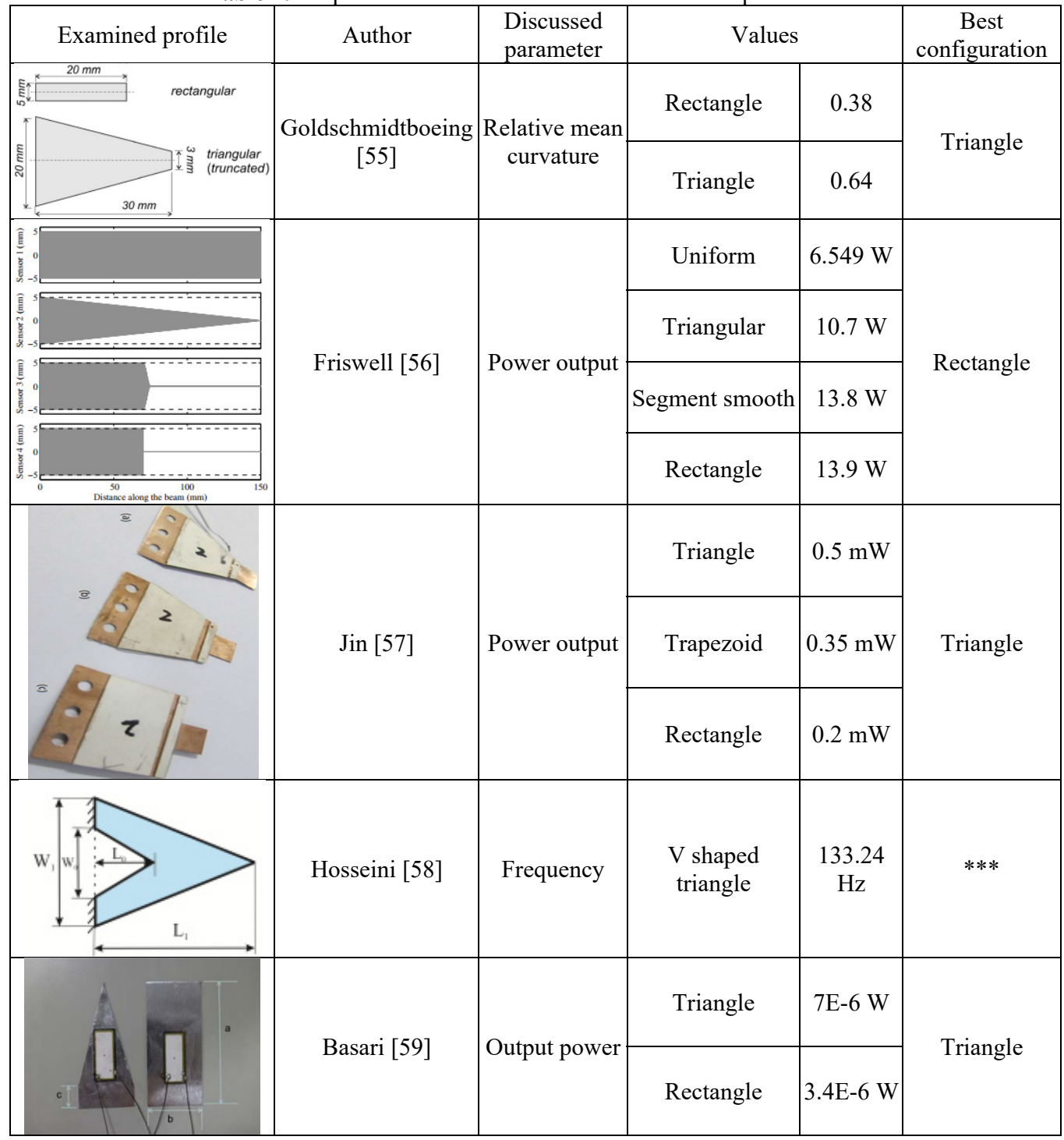

Later M. H. Korayem used the same Hamilton principle in his work for considering the 
parameters, material length selection and piezoelectric voltage effects in the process of development of Atomic Force Microscope cantilever [51].

L. G. H. Staaf et al. proposed a harvesting system and succeeded by producing five times more output than the conventional cantilevers [52]. Many authors have worked to evaluate the performance of various shapes of cantilever beams. Mostly preferred shapes are Rectangle, Triangle, Trapezoid and truncated triangle apart from other configurations like E shaped, L shaped, T shaped cantilevers etc. [53, 54]. Some of the results are summarized in Table 4.

Researchers have concluded that triangular cantilevers produce the maximum vibration when deflected making it suitable for low frequency applications also.

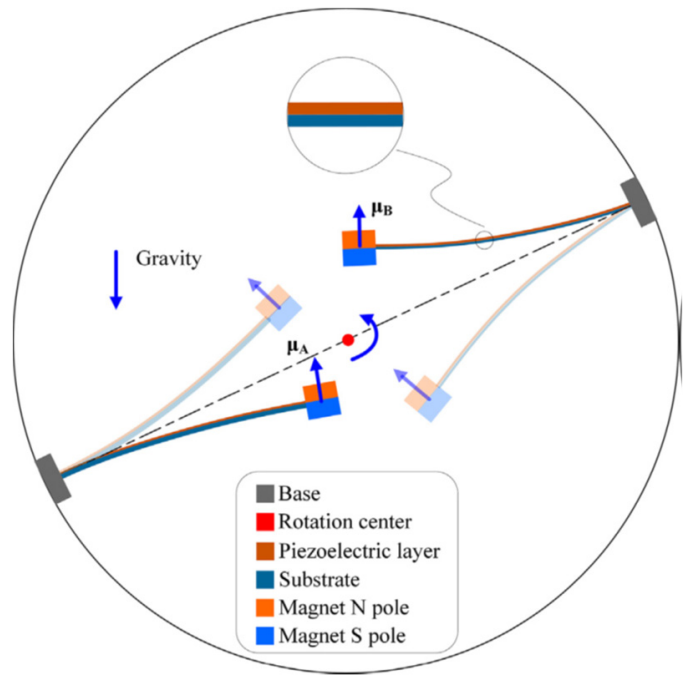

Fig. 13. Schematic diagram of magnetically coupled energy harvester using two inverted piezoelectric cantilever beams [50]

\section{Performance improvement of energy harvesters}

The performance of piezoelectric materials is subject to the stress applied to it. In this section, the reaction of piezoelectric materials when stress is applied onto it in two different directions is studied. Basically, 31mode and 33 mode (Fig. 14(a), (b)) are the two practical coupling modes used which refer to the direction of mechanical stress and charge collection. In 33 mode, the force application is along the polarization axis, but the charge collection is perpendicular to it and vice versa for 31 mode. This type of mode analysis plays a key research in improving the performance. Piezoceramic materials are subjected to fatigue crack growth under high frequency cyclic loading, Lee et al. research suggested that by using a more durable electrode layer, the device can operate under strenuous condition and can harvest more output. The amount of energy harvested can be increased by selecting a proper coupling mode [60]. Xiu-juan et al. investigated and proved that 31 coupling mode cantilevers has proved to be efficient under low vibration level environment while the 33 mode configuration cantilever is suitable in high vibration level sectors [61].

He also proved that the harvested output power is directly proportional to the coupling coefficient $k$ and dielectric constant. Yang et al. research concludes that the device having high coupling coefficient produce more power and that have nearer driving frequency to resonant frequency will leads to more power generation [62]. Cho et al. predicted that by increasing the stiffness of the passive elastic layer will simultaneously increase the coupling coefficient which in-turn leads to more output and at the end his research it was found that the residual stress plays a key role in decreasing the coupling coefficient and concluded that reducing this residual stress will show significant gain in coupling coefficient [63]. 


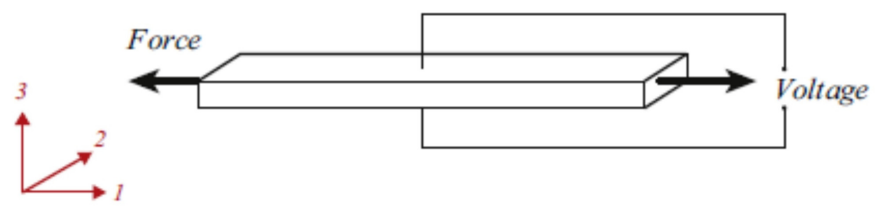

a)

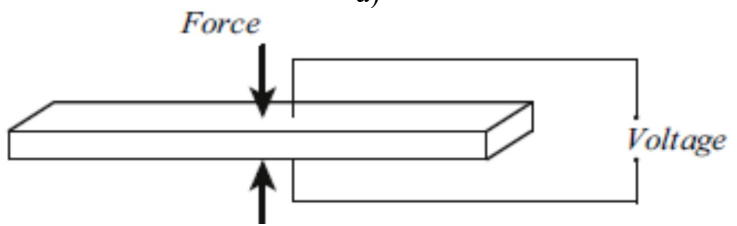

b)

Fig. 14. a) 31 mode of operation, b) 33 mode of operation
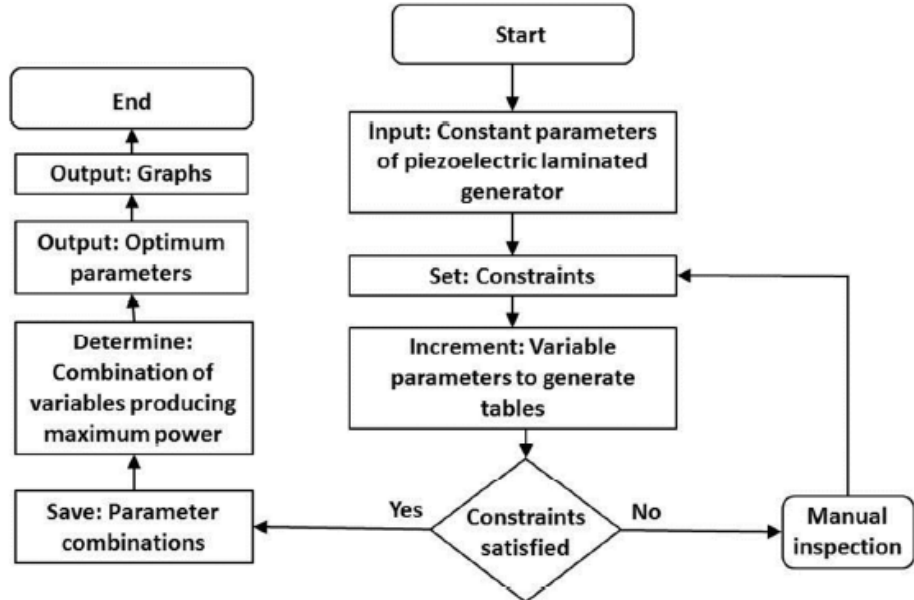

Fig. 15. Flowchart of the proposed algorithm by Mukhanov [19]

The above suggested result is also presented by Roundy et al. which concluded that the resonant frequency of a system that operates at the 31 mode is much lower and leading the system to drive in the natural environment at resonance and thus providing more power [18, 64]. Jiang et al. research states that a stack configuration that contain a large number of thin piezoceramic wafers as stack with the electric field applied along its length provides an increased output and also concluded that both the resistive load and the voltage output are much more manageable than in a monolithic configuration [58].

An energy harvester cannot outperform without using Optimization technique. The vital parameters are identified and put into a proper shape to give the best performance [65]. Mukhanov designed a optimization tool for the voltage generated by a piezoelectric bimorph using Euler Bernoulli's cantilever vibration theory [19].

Cho et al. experimented on thin film piezoelectric membrane generators which are micro machined for improving the performance and finally succeeded in optimizing by increasing the electromechanical coupling coefficient which is affected by residual stress mostly [66]. An energy harvester as shown in Fig. 16 is studied which provides damping to the structure when the vibration structure present acts as an input to harvest energy. The relation between the conversion efficiency the induced damping is discussed. Here optimization is based on the strength of the coupling in the harvester [67].

Using load impedance adaptation principle, G. K. Ottman et al. designed a circuit which optimizes the maximum power transfer in the storage component from the piezoelectric element $[68,69]$. 


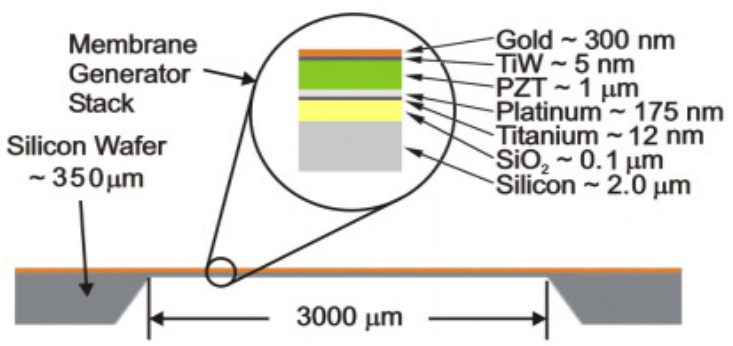

Fig. 16. Thin film piezoelectric membrane generator-cross section [62]

The harvested average power per unit mass is given by [16]:

$\frac{P}{M}=\frac{A^{2}}{w_{s c}} \bar{P}\left(r, \Omega, k_{e}^{2}, \zeta_{m}\right)$

where $\Omega$ - frequency ratio, $A$ - acceleration. $r$ - the normalized electric resistance, $w_{s c}-$ short circuit resonance, $\zeta m$ - mechanical damping ratio, $k_{e}^{2}-$ overall electromechanical coupling coefficient of the system.

Table 5. Investigation of optimized parameters

\begin{tabular}{|c|c|c|}
\hline Author & Optimized parameter & Compared parameters \\
\hline Cho [66] & $\begin{array}{c}\text { Electromechanical coupling } \\
\text { coefficient }\end{array}$ & $\begin{array}{c}\text { Aspect ratio residual stress, side length, electrode } \\
\text { coverage and aspect ratio }\end{array}$ \\
\hline Jiang [24] & Output power density & $\begin{array}{c}\text { Physical dimensions of the piezoelectric material the } \\
\text { frequency }\end{array}$ \\
\hline Mukhanov [19] & Output power & $\begin{array}{c}\text { Area of the piezoelectric material, Piezoelectric } \\
\text { constant }\end{array}$ \\
\hline Ottman [68] & Output power & $\begin{array}{l}\text { Frequency, coupling co efficient of the piezoelectric } \\
\text { material }\end{array}$ \\
\hline Ottman [69] & Duty cycle & Input mechanical excitation \\
\hline Shu $[16]$ & Efficiency & $\begin{array}{l}\text { Electromechanical coupling coefficient, Frequency } \\
\text { ratio, damping ratio, normalized resistance }\end{array}$ \\
\hline
\end{tabular}

\section{MEMS technology}

Decades have recorded significant growth in the development of piezoelectric MEMS (Micro electromechanical systems) technology. Using many improved research methods, fabrication is done to enhance the properties of the piezoelectric materials. Small integrated cantilevers can be fabricated carrying similar properties of giant sensors. Three major techniques are used for the fabrication of MEMS in piezoelectric systems, Sol-Gel technique, Sputter Deposition and Aerosol deposition. The comparison the techniques is given in Table 6 .

Table 6. Comparison of fabrication techniques

\begin{tabular}{|c|c|c|c|}
\hline & Sol-Gel technique [70] & Sputter deposition [71] & Aerosol deposition [72] \\
\hline \multirow{2}{*}{ Advantages } & 1. High purity & 1. High deposition rate & 1. Simple \\
\cline { 2 - 4 } & 2. Composition control & 2.High accuracy & 2. High electromechanical coupling \\
\hline \multirow{2}{*}{ Disadvantages } & 1. Precipitation & 1. High cost & 1. Not compatible \\
\cline { 2 - 4 } & 2. Porosity & 2. Contamination & 2. High temperature required \\
\hline Material & PZT & ZnO, AIN & PZT \\
\hline
\end{tabular}

Lee et al. [72] fabricated a piezoelectric bimorph energy harvester as shown in Fig. 17 and experimented for serial and parallel polarization using two laminated piezoelectric layers. This is done by various proof mass configurations fitted at the tip of the mass for adjusting the resonant 
frequency. He found out serial polarization poling mode generated. $0.23 \mu \mathrm{W}$ more than parallel polarization poling mode. However, the above results are not validated.

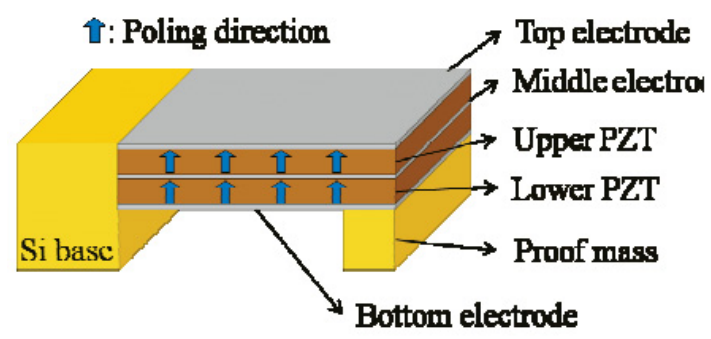

Fig. 17. Piezoelectric bimorph energy harvester [72]

Yuan Luo [73] et al. produced a maximum power of $0.155 \mu \mathrm{W}$ on a bifurcated four cantilever symmetrical structure shown in figure and found power increased with increase in acceleration. Further increase in power was due to optimization of structural parameters. Foruzande et al. [74] modeled a piezoelectric nanobeam, studied its properties and applied with multiple scales method to investigate the effect of non-linearity. Further analysis proved that increase in scale factor is associated with increase in vibration and voltage, nonlinear frequency is also tending to decrease as tip mass is increased. However, all the above results are proved only analytically and not experimentally.

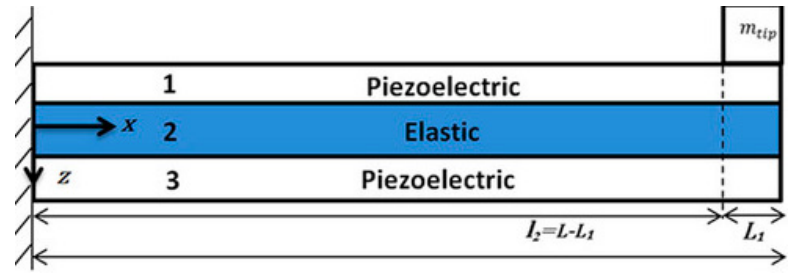

Fig. 18. Piezoelectric nanobeam [74]

Hua Yu et al. [71] fabricated a MEMS piezoelectric vibrator for charge harvesting. He also increased the energy storage capacity efficiency up to $64.95 \%$ using improved voltage regulation. Salem et al. [75] designed a broadband cantilever and analyzed its configuration in coventor. He found the five layered cantilever arrangements can harvest more output than single cantilever.

In order to overcome the difficulty of high voltage consumption by parallel electrodes, Jeo et al. [70], Lee et al [76] and Muralt et al. [77] insisted on the application of inter-digitated electrodes and generated $1.0 \mu \mathrm{W}, 0.123 \mu \mathrm{W}$ and $1.4 \mu \mathrm{W}$ respectively. The thickness of the coating depends on the spinning velocity, spinning cycle and temperature.

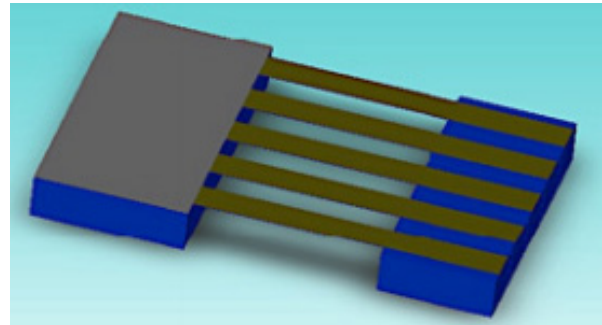

Fig. 19. Coventorware designed piezoelectric vibrator [71]

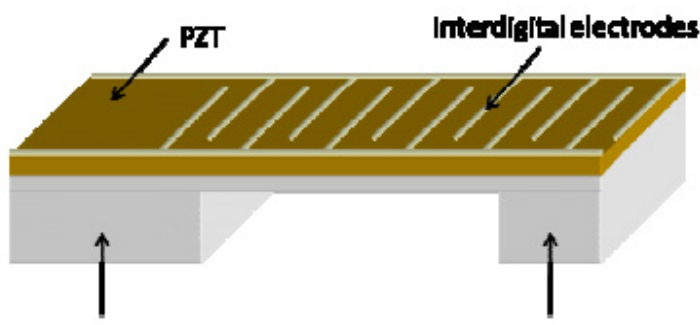

Fig. 20. Interdigitated electrodes impregnated on PZT [76] 
Table 7. Investigation of research findings related to MEMS

\begin{tabular}{|c|c|c|c|c|c|}
\hline Reference & Arrangement & $\begin{array}{l}\text { Power } \\
\text { harvested } \\
\text { (W) }\end{array}$ & $\begin{array}{l}\text { Frequency } \\
\quad(\mathrm{Hz})\end{array}$ & $\begin{array}{l}\text { Method } \\
\text { employed }\end{array}$ & $\begin{array}{l}\text { Piezoelectric } \\
\text { Thickness (m) }\end{array}$ \\
\hline 72 & $\begin{array}{c}\text { Two layers of } \\
\text { Piezoelectric patches } \\
\text { laminated }\end{array}$ & $1.778 \mathrm{E}-06$ & 167.95 & $\begin{array}{c}\text { Aersol } \\
\text { deposition } \\
\text { technique }\end{array}$ & $1.00 \mathrm{E}-05$ \\
\hline 73 & $\begin{array}{c}\text { Symmetrical and } \\
\text { Bifurcate shaped } \\
\text { consisting of four } \\
\text { cantilevers }\end{array}$ & $1.55 \mathrm{E}-04$ & 292.1 & $* * *$ & 4.50E-06 \\
\hline 74 & $\begin{array}{c}\text { PZT and KNN materials } \\
\text { on a stainless steel } \\
\text { cantilever }\end{array}$ & $6.70 \mathrm{E}-06$ & 367 & RF Sputtering & $2-2.5 \mathrm{E}-06$ \\
\hline 71 & $\begin{array}{l}\text { Five piezoelectric } \\
\text { elements each consisting } \\
\text { of top } \mathrm{Al} \text { electrode, } \\
\text { middle PZT layer, and a } \\
\mathrm{Pt} / \mathrm{Ti} \text { bottom electrode. }\end{array}$ & $6.68 \mathrm{E}-05$ & 234.5 & Sputter deposit & $8.00 \mathrm{E}-05$ \\
\hline 75 & $\begin{array}{l}\text { Rectangular piezoelectric } \\
\text { layer with proof mass at } \\
\text { the bottom end }\end{array}$ & $6.80 \mathrm{E}-03$ & $67-70$ & $* * *$ & $1.12 \mathrm{E}-05$ \\
\hline 70 & $\begin{array}{l}\text { Cantilever with proof } \\
\text { mass at the top end and } \\
\text { surface consisting of } \\
\text { Membrane layer, } \\
\text { diffusion barrier and a } \\
\text { PZT layer }\end{array}$ & $1.00 \mathrm{E}-06$ & 13900 & Sol-gel spin & $4.80 \mathrm{E}-07$ \\
\hline 76 & $\begin{array}{c}\text { Rectangulart } \\
\text { piezoelectric layer } \\
\text { consisting of } \\
\text { interdigitated electrodes } \\
\text { on the upper surface }\end{array}$ & $1.23 \mathrm{E}-07$ & 503 & Aersol & $1.20 \mathrm{E}-05$ \\
\hline 77 & $\begin{array}{l}\text { Cantilever with inertial } \\
\text { mass at the bottom end }\end{array}$ & $1.40 \mathrm{E}-06$ & 870 & $* * *$ & $5.00 \mathrm{E}-06$ \\
\hline
\end{tabular}

\section{Conclusions}

There are number of parameters that could bring a remarkable change in improving the output in piezoelectric energy harvesting system using piezoelectric elements [74]. Besides having plenty of advantages like easy rectification and easy fabrication, the greatest challenge one face in harvesting output is the low power output and its integration [80]. An extensive comparative study (Table 2) on the piezoelectric elements to boost the effective power output is done and some of the observations are listed which are the significant contributors on electric output production:

1) The shape and orientation of the fabricated structure or piezoelectric geometry as it influences on more on electric output.

2) The intensity of force applied on the substrate of the piezoelectric layer as amount of stress is directly proportional to the electric power.

3) Multilayered piezoelectric structures provide more output than single layered piezoelectric arrangement.

4) A good vibration source plays an important role in power harvesting.

5) Power conditioning devices are of utmost importance as less electric output is produced

6) 31 mode of piezoelectric operation provides more output when stressed than 33 coupling mode and can be effectively used for low voltage applications.

7) Triangular shaped cantilevers perform high over widely used rectangular cantilevers. 
On investigation, it is clear that piezoelectric elements excited through natural modes get output lesser than those with external forced excitation techniques. It is seen that large scale manufacturing is less common and most of the power harvesters are small scale devices which focus on development of self powered sensors. It is also seen that most of the energy harvesters output require storage, hence rectification plays an important role. Till now it is clear that researchers have focused only on individual parametric improvement and no unique high efficient piezoelectric device has been developed so far. It is in evident that the future piezoelectric harvester design should have high electromechanically coupling and inbuilt power conditioning to avoid power losses. It is no doubt that piezoelectric materials will contribute to the best part of interdisciplinary research in future.

\section{References}

[1] Yang Y., Solgaard H. S., Haider W. Wind, hydro or mixed renewable energy source: Preference for electricity products when the share of renewable energy increases. Energy Policy, Vol. 97, 2016, p. 521-531.

[2] Mohtasham J. Review article-renewable energies. Energy Procedia, Vol. 74, 2015, p. 1289-1297.

[3] Bosch J., Staffell I., Hawkes A. D. Temporally-explicit and spatially-resolved global onshore wind energy potentials. Energy, Vol. 131, Issue 15, 2017, p. 207-217.

[4] Sampaio P. G. V., González M. O. A. Photovoltaic solar energy: conceptual framework. Renewable and Sustainable Energy Reviews, Vol. 74, 2017, p. 590-601.

[5] Macdougall S. L. The value of delay in tidal energy development. Energy Policy, Vol. 87, 2015, p. 438-446.

[6] Khan N., Kalair A., Abas N., Haider A. Review of ocean tidal, wave and thermal energy technologies. Renewable and Sustainable Energy Reviews, Vol. 72, 2017, p. 590-604.

[7] Vinod Tejwania, Bhavik Suthar Power management in fuel cell based hybrid systems. International Journal of Hydrogen Energy, Vol. 42, 2017, p. 14980-14989.

[8] Helseth L. E., Wen H. Z. Evaluation of the energy generation potential of rain cells. Energy, Vol. 119, 2017, p. 472-482.

[9] Røksland M., Basmoen T. A., Sui D. Geothermal energy extraction from abandoned wells. The 8th International Conference on Applied Energy, Vol. 105, 2017, p. 244-249.

[10] Joshi G., Pandey J. K., Rana S., Devendra Rawat S. D. S. Challenges and opportunities for the application of biofuel. Renewable and Sustainable Energy Reviews, Vol. 79, 2017, p. 850-866.

[11] Singh A. K., Parida S. K. A novel hybrid approach to allocate renewable energy sources in distribution system. Sustainable Energy Technologies and Assessments, Vol. 10, 2015, p. 1-11.

[12] Paz F. D. L., Antelo S. A., Soares I. The European low-carbon mix for 2030: the role of renewable energy sources in an environmentally and socially efficient approach. Renewable and Sustainable Energy Reviews, Vol. 48, 2015, p. 49-61.

[13] Mansson A. A resource curse for renewables? Conflict and cooperation in the renewable energy sector. Energy Research and Social Science, Vol. 10, 2015, p. 1-9.

[14] Kokkinopoulos A., Vokas G., Papageorgas P. Energy harvesting implementing embedded piezoelectric generators - the potential for the Attiki Odos traffic grid. Energy Procedia, Vol. 50, 2014, p. 1070-1085.

[15] Khaligh A. Kinetic energy harvesting using piezoelectric and electromagnetic technologies-state of the art. IEEE Transactions on Industrial Electronics, Vol. 57, 2010, p. 850-60.

[16] Shu Y. C., Lien I. C. Efficiency of energy conversion for a piezoelectric power harvesting system. Journal of Micromechanics and Microengineering, Vol. 16, 2006, p. 2429-2438.

[17] Kim H. W., Batra Priya, Uchino Markley, Newnham R. E., Hofmann H. F. Energy harvesting using a piezoelectric 'cymbal' transducer in dynamic environment. Japanese Journal of Applied Physics, Vol. 43, 2004, p. 6178-6183.

[18] Roundy S., Wright P. K., Rabaey J. A study of low level vibrations as a power source for wireless sensor nodes. Journal of Computer Communications, Vol. 26, 2003, p. 1131-1144.

[19] Mukhanov A., Abdigaliyev, Jangeldinov A. B., Zhussip M., Zhapparov R., Ruderman A., Adair D. Development of a design tool for optimization of voltage generation from a bimorph piezoelectric cantilever beam. Materials Today: Proceedings, Vol. 4, 2017, p. 4477-4490. 
[20] Siddique A. R. M. S., Mahmud S., Heyst B. V. A comprehensive review on vibration based micro power generators using electromagnetic and piezoelectric transducer mechanisms. Energy Conversion and Management, Vol. 106, 2015, p. 728-747.

[21] Wei C. F., Jing X. A comprehensive review on vibration energy harvesting: modelling and realization. Renewable and Sustainable Energy Reviews, Vol. 74, 2017, p. 1-18.

[22] Bae J., Lee J., Kim S. M., Ha J., Lee B. S., Park Y. J., Choong C., Kim J. B., Wang Z. L. Flutter-driven triboelectrification for harvesting wind energy. Nature Communications, 2014, https://doi.org/10.1038/ncomms5929.

[23] Junga H. J., Songb Y., Honga S. K., Yanga C. H., Hwanga S. J. S., Sunga T. H. Procedia Increasing the durability of piezoelectric impact-based micro wind generator in real application. Engineering, Vol. 87, 2014, p. 1210-1213.

[24] Jiang S., Li X., Guo S., Hu Y., Yang J., Jiang Q. Performance of a piezoelectric bimorph for scavenging vibration energy. Smart Materials and Structures, Vol. 14, 2005, p. 769-774.

[25] Lee B. S., Lin S. C., Wu W. J. Fabrication and evaluation of a MEMS piezoelectric bimorph generator for vibration energy harvesting. Journal of Mechanics, Vol. 26, 2010, p. 493-499.

[26] Kluger J. M., Moon F. C., Rand R. H. Shape optimization of a blunt body vibro-wind galloping oscillator. Journal of Fluids and Structures, Vol. 40, 2013, p. 185-200.

[27] Fei F., John Maib D. J. D., Li W. J. A wind-flutter energy converter for powering wireless sensors. Sensors and Actuators A, Vol. 173, 2012, p. 163-171.

[28] Li S., Lipson H. Vertical-stalk flapping-leaf generator for wind energy harvesting. ASME Conference on Smart Materials, Adaptive Structures and Intelligent Systems, Vol. 2, 2009, p. 611-619.

[29] Nayak P., Kar D. P., Samal S. K., Mohanty A., Bhuyan S. Excitation of peizoelectric device through resonant helical coil antenna like structure. AEU - International Journal of Electronics and Communications, Vol. 78, 2017, p. 1-6.

[30] Tao J. X., Viet N. V., Carpinteri A., Wang Q. Energy harvesting from wind by a piezoelectric harvester. Engineering Structures, Vol. 133, 2017, p. 74-80.

[31] Robbins W. P., Morris D., Marusic I., Novak T. O. Wind-generated electrical energy using flexible piezoelectric materials. Proceedings of the American Society of Mechanical Engineers, Vol. 14050, 2006, p. 581-590.

[32] Bryant M., Mahtani R. L., Garcia L. E. Wake synergies enhance performance in aeroelastic vibration energy harvesting. Journal of Intelligent Material Systems and Structures, Vol. 23, Issue 10, 2012, p. 1131-1141.

[33] Mccarthy J. M., Deivasigamani A., John S. J., Watkins S., Coman F., Petersen P. Downstream flow structures of a fluttering piezoelectric energy harvester. Experimental Thermal and Fluid Science, Vol. 51, 2013, p. 279-290.

[34] Mccarthy J., Deivasigamani A., Watkins S., John S., Coman F., Petersen P. On the visualization of flow structures downstream of fluttering piezoelectric energy harvesters in a tandem configuration. Experimental Thermal and Fluid Science, Vol. 57, 2014, p. 407-419.

[35] Mccarthy J., Deivasigamani A., Watkin S., John S., Coman F. A parametric study of wind-induced flutter of piezoelectric patches for energy harvesting. 15th Australian International Aerospace Congress, Melbourne, Australia, 2013.

[36] Lya R., Rguitia M., D'astorga S. D., Hajjaji A., Courtoisa C., Lerichea A. Modeling and characterization of piezoelectric cantilever bending sensor for energy harvesting. Sensors and Actuators A, Vol. 168, 2011, p. 95-100.

[37] Fan K., Chang J., Chao F., Pedrycz W. Design and development of a multipurpose piezoelectric energy harvester. Energy Conversion and Management, Vol. 96, 2015, p. 430-439.

[38] Heidrich N., Knöbber F., Polyakov V., Cimalla V., Pletschen W., Sah R. E., Kirste L., Leopold S., Hamp S., Ambacher O., Lebedev V. Corrugated piezoelectric membranes for energy harvesting from aperiodic vibrations. Sensors and Actuators A, Vol. 195, 2013, p. 32-37.

[39] Kurt E., Cottone F., Uzun Y., Orfei F., Mattarelli M., Ozhan D. Design and implementation of a new contactless triple piezoelectrics wind energy harvesters. International Journal of Hydrogen Energy, Vol. 42, 2017, p. 17813-17822.

[40] Wang H., Meng Q. F. Analytical modeling and experimental verification of vibration-based piezoelectric bimorph beam with a tip-mass for power harvesting. Mechanical Systems and Signal Processing, Vol. 36, 2013, p. 193-209.

[41] Fakhzan M. N., Muthalif A. G. A. Harvesting vibration energy using piezoelectric material: modeling, simulation and experimental verifications. Mechatronics, Vol. 23, 2013, p. 61-66. 
[42] Xie X. D., Wu N., Yuen K. V., Wang Q. Energy harvesting from high-rise buildings by a piezoelectric coupled cantilever with a proof mass. International Journal of Engineering Science, Vol. 72, 2013, p. 98-106.

[43] Patel R., Mcwilliam S., Popov A. A. A geometric parameter study of piezoelectric coverage on a rectangular cantilever energy harvester. Smart Materials and Structures, Vol. 20, 2011, p. 85004.

[44] Muthalif A. G. A., Nordin N. H. D. N. Optimal piezoelectric beam shape for single and broadband vibration energy harvesting:Modeling, simulation and experimental results. Mechanical Systems and Signal Processing, Vol. 54, 2017, p. 417-426.

[45] Maaspuro M. Piezoelectric oscillating cantilever fan for thermal management of electronics and LEDs - A review. Microelectronics Reliability, Vol. 63, 2016, p. 342-353.

[46] Chen N., Jungb H. J., Jabbarb H., Sungb T. H., Wei T. A piezoelectric impact-induced vibration cantilever energy harvester from speed bump with a low-power power management circuit. Sensors and Actuators A, Vol. 254, 2017, p. 134-144.

[47] Prashanthia K., Miriyalaa N., Gaikwada R. D., Moussac W., Rao V. R., Thundata T. Vibrational energy harvesting using photo-patternable piezoelectric nano composite cantilevers. Nano Energy, Vol. 2, Issue 5, 2013, p. 923.

[48] Zhao X., Shang Z., Luo G., Deng L. A vibration energy harvester using AlN piezoelectric cantilever array. Micro Electronic Engineering, Vol. 142, 2015, p. 47-51.

[49] Tang L., Doussis M. P. P., Jiang J. Cantilevered flexible plates in axial flow:Energy transfer and the concept of flutter-mill. Journal of Sound and Vibration, Vol. 326, 2009, p. 263-276.

[50] Zou H. X., Zhang W. M., Li W. B., Wei K. X., Gao Q. H., Peng Z. K., Meng G. Design and experimental investigation of a magnetically coupled vibration energy harvester using two inverted piezoelectric cantilever beams for rotational motion. Energy Conversion and Management, Vol. 148, 2017, p. 1391-1398.

[51] Korayem A. H., Kianfar A., Korayem M. H. The size-dependent analysis of multilayer microcantilevers using MCS theory considering the various surface geometries. European Journal of Mechanics/A Solids, Vol. 61, 2017, p. 59-72.

[52] Staaf Kohler Parthasarathy Lundgren E. D. P., Enoksson P. Simulation and experimental demonstration of improved efficiency in coupled piezoelectric cantilevers by extended strain distribution. Sensors and Actuators A, Vol. 229, 2015, p. 136-140.

[53] Saadon S., Sidek O. Comparative study on standard geometrical structures of cantilever-based MEMS piezoelectric energy harvester over T-shaped cantilever beam for low frequency ambient vibrations. Journal of Optoelectronics Advanced Materials, Vol. 16, 2014, p. 612-618.

[54] Zhang J., Fang Z., Shu C., Zhang J., Zhang Q., Li C. A rotational piezoelectric energy harvester for efficient wind energy harvesting. Sensors and Actuators A: Physical, Vol. 262, 2017, p. 123-129.

[55] Goldschmidtboeing F., Woias P. Characterization of different beam shapes for piezoelectric energy harvesting. Journal of Micromechanics and Microengineering, Vol. 18, 2008, p. 104013.

[56] Friswell M., Adhikari S. Sensor shape design for piezoelectric cantilever beams to harvest vibration energy. Journal of Applied Physics, Vol. 108, 2010, p. 14901.

[57] Jin L., Shiqiao Gao1 S., Zhou1x, Zhang G. The effect of different shapes of cantilever beam in piezoelectric energy harvesters on their electrical output. Microsystem Technologies, Vol. 23, 2017, p. $4805-4814$.

[58] Hosseinia R., Hamedi M. Resonant frequency of bimorph triangular V-shaped piezoelectric cantilever energy harvester. Journal of Computational and Applied Research in Mechanical Engineering, Vol. 6, 2016, p. 65-73.

[59] Amat Basari A. A. A., Awaji S., Wang S., Seiji Hashimoto S., Shunji Kumagai S., Suto S. K., Okada H., Okuno H., Homma B., Jiang W., Shuren Wang S. Shape effect of piezoelectric energy harvester on vibration power generation. Journal of Power and Energy Engineering, Vol. 2, 2014, p. 117-124.

[60] Lee C. S., Joo J., Han S., Lee J. H., Koh S. K. Poly (vinylidene fluoride) transducers with highly conducting poly (3, 4 ethylene di oxy thiophene) electrodes. Proceedings of International Conference on Science and Technology of Synthetic Metals, Vol. 152, 2005, p. 49-52.

[61] Lin X. J., Zhou K. C., Zhang X. Y., Zhang D. Development, modeling and application of piezoelectric fiber composites. Transactions of Nonferrous Metals Society of China, Vol. 23, 2013, p. $98-107$. 
[62] Yang J., Zhou H., Hu Y., Jiang Q. Performance of a piezoelectric harvester in thickness-stretch mode of a plate. IEEE Transactions on Ultrasonics, Ferroelectrics, and Frequency, Vol. 52, 2005, p. $1872-1876$.

[63] Cho J., Anderson M., Richards R., Bahr D., Richards C. Optimization of electromechanical coupling for a thin-film PZT membrane: I modeling. Journal of Micromechanics and Microengineering, Vol. 15, 2005, p. 1797-1803.

[64] Anton S. R., Sodano H. A. A review of power harvesting using piezoelectric materials (2003-2006). Smart Materials and Structures, Vol. 16, 2007, https://doi.org/10.1088/0964-1726/16/3/R01.

[65] Franco V. R., Varoto P. S. Parameter uncertainties in the design and optimization of cantilever piezoelectric energy harvesters. Mechanical Systems and Signal Processing, Vol. 93, 2017, p. 593-609.

[66] Cho J., Anderson M., Richards R., Bahr D., Richards C. J. Optimization of electromechanical coupling for a thin-film PZT membrane: II experiment. Journal of Micromechanics and Microengineering, Vol. 15, 2005, p. 1804-1809.

[67] Lesieutre G. A., Ottman G. K., Hofmann H. F. Damping as a result of piezoelectric energy harvesting. Journal of Sound and Vibration, Vol. 269, 2004, p. 991-1001.

[68] Ottman G. K., Hofmann H. F., Bhatt A. C., Lesieutre G. A. Adaptive piezoelectric energy harvesting circuit for wireless remote power supply. IEEE Transactions on Power Electronics, Vol. 17, 2002, p. 669-676.

[69] Ottman G. K., Hofmann H. F., Lesieutre G. A. Optimized piezoelectric energy harvesting circuit using step-down converter in discontinuous conduction mode. IEEE Transactions on Power Electronics, Vol. 18, 2003, p. 696-703.

[70] Jeon Y. B., Soodb R., Jeong J., Kim G. MEMS power generator with transverse mode thin film PZT. Sensors and Actuators A, Vol. 122, 2005, p. 16-22.

[71] Yu H., Jielin Zhou J., Deng Land Wen Z. A vibration-based MEMS piezoelectric energy harvester and power conditioning circuit. Sensors, Vol. 14, 2014, p. 3323-3341.

[72] Roundy E., Wright P. K. P. K. A piezoelectric vibration based generator for wireless electronics. Smart Materials and Structures, Vol. 13, 2004, p. 1131-1142.

[73] Luo Y., Gan R., Wan S., Xu R., Zhou H. Design and analysis of a MEMS-based bifurcate-shape piezoelectric energy harvester. AIP Advances, Vol. 6, 2016, p. 45319.

[74] Kanno I. Piezoelectric MEMS for energy harvesting. Journal of Physics: Conference Series, Vol. 660, 2015, p. 12001.

[75] Saadona S., Sideka O. Micro-electro-mechanical system (MEMS)-based piezoelectric energy harvester for ambient vibrations. Procedia - Social and Behavioral Sciences, Vol. 195, 2015, p. 2353-2362.

[76] Lee B. S., Wu W. J., Shihw P., Vasic D., Costa F. Power harvesting using piezoelectric MEMS generator with interdigital electrodes. IEEE Ultrasonics Symposium, 2007.

[77] Muralta P., Marzenckib M., Belgacema B., Calamea F., Basrourb S. Vibration energy harvesting with PZT micro device. Procedia Chemistry, Vol. 1, Issue 1, 2009, p. 1191-1194.

[78] Li S., Crovetto A., Peng Z., Zhang A., Hansen O., Wang M., Li X., Wang F. Bi-resonant structure with piezoelectric PVDF films for energy harvesting from random vibration sources at low frequency. Sensors and Actuators A: Physical, Vol. 247, 2016, p. 547-554.

[79] Zhao J., Yang J., Lin Z., Zhao N., Liu J., Wen Y., Li P. An arc-shaped piezoelectric generator for multi-directional wind energy harvesting. Sensors and Actuators A: Physical, Vol. 236, 2015, p. 173-179.

[80] Chunga H. C., Kummaria L., Croucherb S. J., Lawsonb N. J., Guob S., Whatmorec R. W., Huang Z. Development of piezoelectric fans for flapping wing application. Sensors and Actuators A, Vol. 149, 2009, p. 136-142.

[81] Chen N., Wei T., Jung H. J., Lee S. Quick self-start and minimum power-loss management circuit for impact-type micro wind piezoelectric energy harvesters. Sensors and Actuators A Vol. 263, 2017, p. 23-29.

[82] Li S., Yuan J., Lipson H. Ambient wind energy harvesting using cross flow fluttering. Journal of Applied Physics, Vol. 109, 2011, p. 26104. 


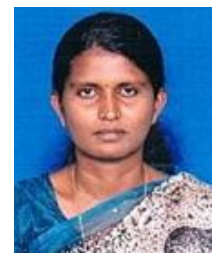

Varadha E received M.E. degree in energy engineering from Anna University of Technology, Tirunelveli, in 2011. Now she is pursuing her Ph.D. at Anna University Chennai. Her current research interests include wind energy, piezoelectric materials.

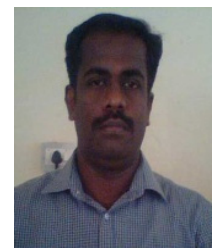

Rajakumar S received Ph.D. degree from Anna University Chennai, in 2013. Now he works at Anna University Tirunelveli campus. His current research interests include wind energy, energy auditing. 